\title{
Effects of Power Distance on Organizational Commitment: A Study on Maritime Faculty Students
}

\author{
(1) Umut Yıldırım¹, ๑ Arda Toygar², (1) Ahmet Lutfi Tunçel ${ }^{3}$ \\ ${ }^{1}$ Karadeniz Technical University Surmene Faculty of Marine Sciences, Department of Maritime Transportation and \\ Management Engineering, Trabzon, Turkey \\ ${ }^{2}$ Artvin Coruh University Hopa Vocational School, Maritime and Port Management Program, Artvin, Turkey \\ ${ }^{3}$ İstanbul Technical University Maritime Faculty, Department of Maritime Transportation and Management Engineering, \\ İstanbul, Turkey
}

\begin{abstract}
This study investigates the effect of power distance on the organizational commitment of maritime faculty students. The hypotheses developed in this context were analyzed using the structural equation modeling method based on data collected from 406 participants. The results from one-dimensional (1D) evaluation indicated that organizational power distance had a positive impact on the organizational commitment levels of maritime faculty students. However, there are several studies in the literature that show that this effect may lead to inconsistent results in 1D examination. These conflicting results necessitate a multidimensional analysis of the research. Evaluation of the sub-dimensions included in the study revealed that: (1) acceptance of power had positive effects on calculative and moral commitment, (2) justification of power on moral commitment, and (3) acquiescence of power on calculative, alienative, and moral commitment.
\end{abstract}

Keywords

Organizational commitment, Power distance, Maritime, Education, Vocational training

\section{Introduction}

Although various factors that influence the academic performance of students have been discussed in the literature, the commitment of students to the educational institution is the most important one [1,2]. Because it increases students' loyalty levels, leading to superior performance [3]. Besides, powerful commitments that individuals establish with their superior managers also positively affect their performance [4]. Educational institutions, defined as organizations for students, are both centers of science and theoretical knowledge and essential business partners that benefit working life. Vocational education differs from traditional education, integrating with working life [5]. Maritime faculties provide vocational education in cooperation with the maritime industry. Maritime customs play a significant role in the formation of this educational understanding [6]. These manners and traditions emerged due to the requirements of marine life experienced and learned on ships throughout history. Moreover, maritime faculty students spend at least 6 to 12 months on a maritime internship during their undergraduate education, which differentiates them from students in other departments. Although the education understanding in maritime faculties differs significantly from that in other faculties, few studies in the literature examine the effects of this difference on students' levels of organizational commitment. Maritime faculties are among organizations that encourage hierarchical formation and subordinate-superior relationships based on specific rules, where the power distance difference is important. The literature has reported that organizations with a high power distance have negative effects on individuals [7]. Conversely, some studies revealed that organizations with high power distance levels positively affected individuals [8]. In order to eliminate this inconsistency, a multidimensional analysis should be used to investigate the impact of power

\footnotetext{
Address for Correspondence: Umut Ylldırım, Karadeniz Technical University Surmene Faculty of Marine Sciences, Department of Maritime Transportation and Management Engineering, Trabzon, Turkey

E-mail: uyildirim@ktu.edu.tr

ORCID ID: orcid.org/0000-0002-3991-5457
}

Received: 17.08 .2021

Accepted: 05.11 .2021

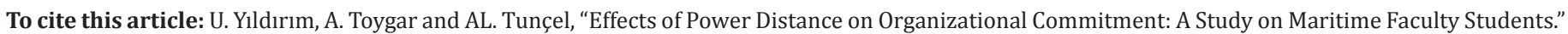
Journal of ETA Maritime Science, vol. 9(4), pp. 256-265, 2021.

${ }^{\mathcal{C}}$ Copyright 2021 by the Journal of ETA Maritime Science published by UCTEA Chamber of Marine Engineers 
distance on organizational commitment levels. In models where organizational power distance and commitment are constructed in one dimension (1D), the results do not represent the relevant concepts in either theoretical or practical frameworks [9]. Therefore, in the current study, the multidimensional analysis was applied to investigate the effects of power distance on students' organizational commitment. Unlike 1D evaluation, the results of this study suggest that organizational power distance can have a positive impact on organizational commitment. Further, this study is one of the first systematic attempts to investigate the organizational commitment levels of maritime faculty students in organizations with high power distances.

This paper is divided into the following sections: in the second section, the concepts related to the subject of the study are explained, and the literature studies are discussed. The third section includes arguments supporting the hypothetical effect of power distance on organizational commitment and its sub-dimensions, as well as the proposed research hypotheses and model. The fourth and fifth sections include the research methodology, analysis, and findings. The conclusion section presents the results of the study, its implications, and recommendations for future studies.

\section{Concepts and Theoretical Background}

\subsection{Organizational Power Distance}

The concept of power distance has been defined in different contexts. According to one of these definitions, it can be expressed as the extent to which individuals perceive themselves as equal to the rest of society [10]. In other words, power distance shows how societies handle the fact that people are not seen as similar when considering all their characteristics [11]. Besides, the formation of organizations shaped by society is another definition of power distance. Various factors determine the power distance perceptions of societies. For example, in addition to the status of individuals, the belief and cultural structure of a society can also affect individuals' perception of power [12]. Power distance is significant in social life, including work, education, and other organizational structures where hierarchical structures are constructed. Moreover, organizational power distance significantly affects the relationships between individuals who do not have the same power level. Hofstede [13] stated that while the subordinate-superior relationship in workplaces has an educational and practical basis in societies with a low power distance, the cause of this relationship was primarily emotional in societies with a high power distance.

\subsection{Organizational Commitment}

The commitment of individuals to their organizations is very significant for organizations, leading organizational commitment as one of the main topics in the related literature [14]. Organizational commitment is defined as the commitment of individuals to the organization that they work for [15]. There are various definitions and perspectives of organizational commitment in the literature. Sheldon [16] defined organizational commitment as an evaluation of the goals set by the organization from a positive perspective, whereas Buchanan [17] defined it as an emotional bond developed with the structure of the organization. Çöl and Gül [18] suggested that the reason for different evaluations of organizational commitment in the literature is the interpretation of this concept from different perspectives by other disciplines, such as psychology, sociology, and organizational behavior. There are several theories in the literature on organizational commitment. Etzioni [19] argued that the foundations of organizational commitment were constructed by categorizing it as alienative, moral, and calculative. Penley and Gould [20], investigating the basis of these three concepts, proposed that alienative and moral commitment can reveal emotional aspects of individuals while calculative commitment can determine instrumental aspects.

\section{Theoretical Basis and Research Hypotheses}

There are numerous studies in the literature on the effects of power distance on individuals' organizational commitment. Some studies argue that organizations with a high power distance negatively affect the commitment levels of individuals [21]. For instance, Ylldırım and Deniz [22] analyzed these effects based on data collected from 1094 participants. According to the results of their analysis, it was concluded that organizational power distance had a negative effect on commitment levels. However, other studies showed that organizations with a high power distance have a positive impact on commitment levels [23]. For example, a study by Din et al. [24] using data collected from 300 participants indicated that commitment levels would be high in organizations with a high power distance. The main hypothesis developed in the present study to eliminate this inconsistency in the literature is as follows:

$H_{1}$ : Organizational power distance has a positive effect on the organizational commitment levels of maritime faculty students.

To fully examine the concept of organizational power distance, the sub-dimensions of acceptance power, instrumental use of power, justification of power, and acquiescence of power developed by Yorulmaz et al. [12] were used in the present study. For organizational commitment, 
we used the sub-dimensions of calculative commitment, alienative commitment, and moral commitment developed by Penley and Gould [20]. Acceptance of power is the acquiescence of individuals working at different levels in the same organization to the unequal power distribution [12]. Calculative commitment is when the organization is used as a tool to achieve an individual's targeted interests [25]. Duska [26] defined alienative commitment as the lowest commitment level. Conversely, those with alienative commitment have to be in the organization, even if they cannot be internalized and cannot establish a relationship with it. Etzioni [19] argued that the strongest commitment type is a moral commitment. In moral commitment, individuals in the organization give precedence to the goals of the organization, internalizing them in their voluntary willingness to serve the organization [27]. Jaros et al. [9] argued that individuals with a high moral commitment level have an increased sense of duty and a high organizational commitment level. Thus, the following sub-hypotheses are developed:

$H_{1.1}$ : Acceptance of power has a positive effect on the calculative commitment levels of maritime students.

$H_{1.2}$ : Acceptance of power has a positive effect on the alienative commitment levels of maritime students.

$H_{1.3}$ : Acceptance of power has a positive effect on the moral commitment levels of maritime students.

Instrumental use of power neglects ethical values in the struggle to achieve determined goals [28]. According to this understanding, an individual contributes to the organization to benefit from the opportunities provided. The possibilitycontribution exchange realized by the individual to achieve their goal constitutes the concept of instrumental commitment. In cases where such an understanding is seen in an organization, superiors need to understand the culture of the organization and protect its interests [29]. Also, the level of instrumental use of power corresponds to the ratio of the organization's demands met by the individual [20]. For this reason, the following sub-hypotheses are proposed to determine the effects of instrumental use of power on the organizational commitment of maritime students:

$H_{1.4}$ : Instrumental use of power has a positive effect on the calculative commitment levels of maritime students.

$H_{1.5}$ : Instrumental use of power has a positive effect on the alienative commitment levels of maritime students.

$H_{1.6}$ : Instrumental use of power has a positive effect on the moral commitment levels of maritime students.

Justification of power is such that the individuals working in managerial positions make employees accept their authority on legal grounds. In addition to the search for legal grounds, identifying societies' cultural structures and positions with individuals leads to the justification of power [30]. Wang et al. [8] emphasized that the relationship between subordinates and superiors can affect their organizational commitment levels; this effect will be a determining factor for the performance levels of subordinates. Moreover, Bedürk and Ertürk [31] argued that organizational power distance and its sub-dimensions are likely to be high when subordinates accept the leadership of their superiors in the intra-organizational subordinate-superior relationship. Furthermore, Pomyalova et al. [32] determined that the culture formed in the hierarchical structure directly reduces students' commitment levels. Thus, considering the inconsistency in the literature, the following sub-hypotheses are proposed:

$H_{1.7}$ : Justification of power has a positive effect on the calculative commitment levels of maritime students.

$H_{1.8}$ : Justification of power has a positive effect on the alienative commitment levels of maritime students.

$H_{1.9}$ : Justification of power has a positive effect on the moral commitment levels of maritime students.

Acquiescence of power is defined as acquiescence of superior dominance in the groups with hierarchical structure [33]. Acquiescence of power emerges from the perception that the probability of changing management practices is weak in societies where fear is dominant or the potential to encounter risks is high. Randall [34] deduced that a high level of fear toward an organization could have a negative impact on both individuals and the organization. The following sub-hypotheses are proposed:

$H_{1.10}$ : Acquiescence of power has a positive effect on the calculative commitment levels of maritime students.

$H_{1.11}$ : Acquiescence of power has a positive effect on the alienative commitment levels of maritime students.

$H_{1.12}$ : Acquiescence of power has a positive effect on the moral commitment levels of maritime students.

In this study, multidimensional evaluation was applied to investigate the effects of power distance on organizational commitment in the context of the main and sub-dimensions. The structures and interdimensional relations in the proposals were created using literature. Figure 1 presents the proposed models and hypotheses.

\section{Methodology}

\subsection{Instrument and Questionnaire Design}

The online questionnaire method was used as the primary data collection to examine all aspects of the topic used in this research, and two different scales with appropriate features were applied. The first scale is the "organizational power distance scale (OPDS)," prepared by Yorulmaz et al. [12], 
and the second scale is the "organizational commitment scale (OCS)" developed by Penley and Gould [20] and translated into Turkish by Ergün and Çelik [27]. The items in the scales were scored using the 5-point Likert format, where 1 indicates "I strongly disagree" and 5 indicates "I strongly agree."

\subsection{Sampling and Data Collection}

The research population consists of the maritime faculty students in Turkey. The sampling method used in this study is non-probability sampling, also known as convenience sampling, where data is collected from the participants until the desired number of participants is reached. The questionnaire forms were collected from the participants between November and December 2020 using web-based questionnaire method. Among 434 questionnaires collected, 28 were excluded due to incomplete or incorrect or a lack of consistency. Thus, the sampling group in this study consists of 406 questionnaires, i.e., $93.5 \%$ of the completed questionnaires. Regarding the demographic distribution of the sampling group, the majority of the respondents (54.4\%) are aged between 20 and 22 , with $24.9 \%$ in the $1^{\text {st }}$ grade, $20 \%$ in the $2^{\text {nd }}$ grade, $22.9 \%$ in the $3^{\text {rd }}$ grade, $25.6 \%$ in the $4^{\text {th }}$ grade, and $6.7 \%$ in the $5^{\text {th }}$ grade. Examining the distribution of academics considered as managers by the respondents, $7.8 \%$ of students consider their advisor as a manager, with $7.7 \%$ for research assistants, $14.1 \%$ for faculty members, $30.7 \%$ for the head of the department, $21 \%$ for the dean, and $18.5 \%$ for the rector.

\subsection{Sample Size Calculation}

According to the sample size table developed by Sekaran and Bougie [35], when the research population is larger than 1 million, 384 participants can adequately represent

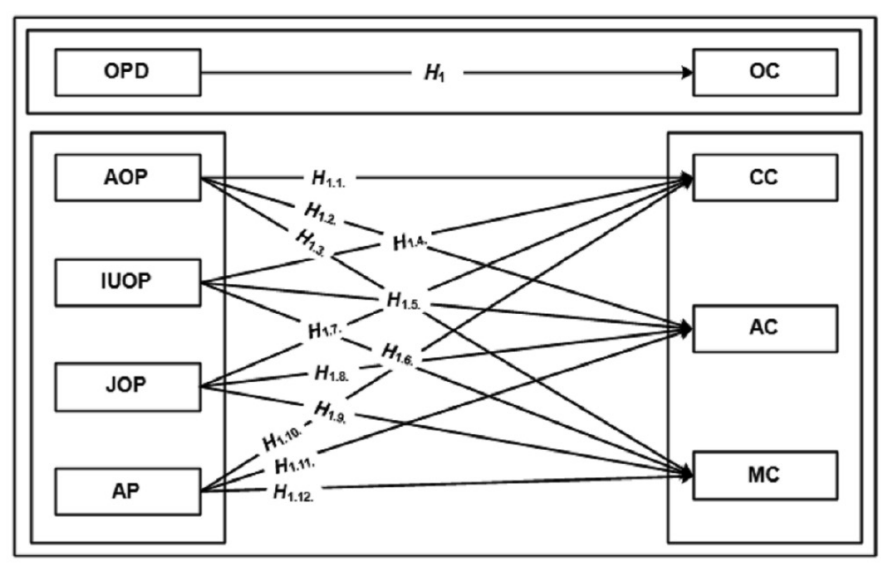

Figure 1. Research model

OPD: Organizational power distance, OC: Organizational commitment, AOP: Acceptance of power, IUOP: Instrumental use of power, JOP: Justification of power, AP: Acquiescence of power, CC: Calculative commitment, AC: Alienative commitment, MC: Moral commitment the research population. Prior to data collection, the target number of participants for the sample size was referenced based on Sekaran and Bougie's [35] study in the literature. In addition, to determine whether the sample size was sufficient for the research after the data collection, a power analysis was carried out using the "Power-3.1.9.2" software. Following data collection, the analysis was performed at an $80 \%$ confidence level. Accordingly, the effect size of the study was calculated using post-hoc (linear multiple regression) power analysis based on the explanatory power of the hypotheses that were found to be significant in the SEM analysis. Using the lowest effect size of 0.015 , the power of the research was determined to be 0.70 . According to Cohen [36], the minimum value required in studies involving post-hoc power analysis is 0.67 . Given that the statistical power for the related post-hoc power analyses ranged between 0.75 and 0.99 , it was determined that the study reached a sufficient number of samples. The results indicated that a sample group of 406 participants would adequately represent the research population.

\section{Results}

\subsection{Confirmatory Factor Analysis Findings for The OPDS and OCS}

Confirmatory factor analysis (CFA) was performed based on the data obtained from the 406 participants to examine the validity of factor structures explained by OPDS and OCS using the primary data and to determine if the original structure of the scales matched with the data collected [37]. In this context, two different measurement models, the OPD ( 4 sub-dimensions 17 items) and the OC ( 3 sub-dimensions 13 items) scales, were tested with CFA analysis. Tables 1 and 2 summarize the results of the analysis.

According to the CFA results, the factor loadings of the items vary between 0.65 and $0.96,0.70$ and 0.95 , respectively, for OPDS and OCS, as presented in Table 1. These standardized factor loadings are significant at the 0.001 level [38]. In this study, the method proposed by Bagozzi and Yi [39] was used to obtain reliable results from structural equation modeling analysis. The average variance extracted (AVE) and composite reliability (CR) values were examined to determine the convergent validity of the measurement models. Table 2 shows that the AVE values for the subdimensions of OPDS and OCS vary between 0.63 and 0.80 , including the CR varies between 0.83 and 0.98 , indicating that the AVE is at satisfactory levels for convergent validity and the CR is considerably above the lower limit [40]. The internal consistency of the sub-dimensions of the OPDS was determined using Cronbach's alpha reliability analysis. To achieve reliable results, the Cronbach's alpha values of the sub-dimensions of the scale should be greater than 0.70 
[41]. The results of the analysis showed that the reliability levels of the sub-dimensions were $0.83,0.86,0.84$, and 0.92 . When the same method was used to the OCS, the subdimensions were $0.86,0.88$, and 0.90 . It was concluded that the reliability for all sub-dimensions was considerably higher than the specified lower limit. Table 2 shows the fit index criteria obtained from the CFA values of the OPDS and OCS.

For the scale to be accepted, the goodness of fit criteria must be greater than the minimum acceptable limits.

Table 1. Standardized item loadings, AVE, CR, and Alpha values

\begin{tabular}{|c|c|c|c|c|c|c|}
\hline Scale & Sub dimension & Item & Factor loading (CFA) & AVE & CR & Cronbach's Alpha \\
\hline \multirow{17}{*}{ OPDS } & \multirow{6}{*}{ AOP } & AOP1 & 0.96 & \multirow{6}{*}{0.63} & \multirow{6}{*}{0.91} & \multirow{6}{*}{0.83} \\
\hline & & AOP2 & 0.65 & & & \\
\hline & & AOP3 & 0.88 & & & \\
\hline & & AOP4 & 0.66 & & & \\
\hline & & AOP5 & 0.78 & & & \\
\hline & & AOP6 & 0.78 & & & \\
\hline & \multirow{3}{*}{ IUOP } & IUOP1 & 0.85 & \multirow{3}{*}{0.69} & \multirow{3}{*}{0.87} & \multirow{3}{*}{0.86} \\
\hline & & IUOP2 & 0.75 & & & \\
\hline & & IUOP3 & 0.89 & & & \\
\hline & \multirow{3}{*}{ JOP } & JOP1 & 0.95 & \multirow{3}{*}{0.69} & \multirow{3}{*}{0.87} & \multirow{3}{*}{0.84} \\
\hline & & JOP2 & 0.73 & & & \\
\hline & & JOP3 & 0.80 & & & \\
\hline & \multirow{5}{*}{$\mathrm{AP}$} & AP1 & 0.90 & \multirow{5}{*}{0.70} & \multirow{5}{*}{0.96} & \multirow{5}{*}{0.92} \\
\hline & & AP2 & 0.85 & & & \\
\hline & & AP3 & 0.83 & & & \\
\hline & & AP4 & 0.81 & & & \\
\hline & & AP5 & 0.80 & & & \\
\hline \multirow{13}{*}{ OCS } & \multirow{3}{*}{$\mathrm{CC}$} & $\mathrm{CC} 1$ & 0.95 & \multirow{3}{*}{0.63} & \multirow{3}{*}{0.83} & \multirow{3}{*}{0.86} \\
\hline & & $\mathrm{CC} 2$ & 0.70 & & & \\
\hline & & $\mathrm{CC} 3$ & 0.71 & & & \\
\hline & \multirow{5}{*}{$\mathrm{AC}$} & AC1 & 0.94 & \multirow{5}{*}{0.80} & \multirow{5}{*}{0.98} & \multirow{5}{*}{0.88} \\
\hline & & $\mathrm{AC} 2$ & 0.90 & & & \\
\hline & & AC3 & 0.90 & & & \\
\hline & & $\mathrm{AC} 4$ & 0.90 & & & \\
\hline & & AC5 & 0.82 & & & \\
\hline & \multirow{5}{*}{ MC } & MC1 & 0.89 & \multirow{5}{*}{0.73} & \multirow{5}{*}{0.96} & \multirow{5}{*}{0.90} \\
\hline & & MC2 & 0.85 & & & \\
\hline & & MC3 & 0.87 & & & \\
\hline & & MC4 & 0.83 & & & \\
\hline & & MC5 & 0.83 & & & \\
\hline $\begin{array}{l}\text { OPDS: Organ } \\
\text { of powe }\end{array}$ & ower distance s & izatior & $\begin{array}{l}\text { t scale, AOP: Acceptanc } \\
\text { lienative commitment, } \\
\text { natory factor analysis }\end{array}$ & ; IUOP & $\begin{array}{l}\text { ntal us } \\
\text { F. Ave }\end{array}$ & $\begin{array}{l}\text { wer, JOP: Justification } \\
\text { rriance extracted, }\end{array}$ \\
\hline
\end{tabular}

Table 2. The recommended and actual values of fit indices

\begin{tabular}{|c|c|c|c|c|c|c|c|c|c|}
\hline Fit criteria & $\chi^{2} / \mathrm{df}$ & RMSEA & CFI & GFI & AGFI & NNFI & NFI & RMR & SRMR \\
\hline Recommended values & $\leq 3^{* * *}$ & $<0.10^{* *}$ & $\geq 0.9^{* *}$ & $\leq 1^{* *}$ & $\leq 1^{* *}$ & $\leq 1^{* *}$ & $\geq 0.9^{*}$ & $\leq 0.10^{* *}$ & $\leq 0.05^{* *}$ \\
\hline Actual values (OPDS) & 2,574 & 0.062 & 0.98 & 0.93 & 0.91 & 0.98 & 0.97 & 0.051 & 0.043 \\
\hline Actual values (OCS) & 2,779 & 0.066 & 0.99 & 0.94 & 0.91 & 0.98 & 0.98 & 0.048 & 0.041 \\
\hline $\begin{array}{l}\text { OPDS: Organizational pow } \\
\text { CFI: Comparative }\end{array}$ & $\begin{array}{l}\text { e scal } \\
\text { GFI: } A\end{array}$ & $\begin{array}{l}\text { yanizatic } \\
\text { podness }\end{array}$ & $\begin{array}{l}*[40],{ }^{*} \\
\text { nitment } \\
\text { ex, RMR }\end{array}$ & $\begin{array}{l}* *[43] . \\
\text { MSEA: }\end{array}$ & lean & err & oxin & Gooc & f-fit index, \\
\hline
\end{tabular}


When the fit criteria values for the OPDS were obtained, it was determined that the most crucial fit value, the ratio of $\mathrm{X}^{2}$ to standard deviation (SD), was at the perfect level (2.574), the RMSEA value (0.062) was at an acceptable level, and the other fit values were also at perfect and acceptable levels $[42,43]$. When the CFA results for the OCS were examined, it was found that the ratio of $\mathrm{X}^{2}$ to sd was at the perfect level (2.779), the RMSEA value (0.066) was at an acceptable level and the other fit values were at perfect and acceptable levels. These results show that the factor structures explained for both OPDS and OCS were validated $[40,42,43]$.

Table 3. Main hypothesis results

\begin{tabular}{|c|c|c|c|c|}
\hline $\begin{array}{c}\text { Structural } \\
\text { path }\end{array}$ & Hypothesis & $\begin{array}{c}\text { Standard } \\
\text { value }\end{array}$ & T-value & $\begin{array}{c}\text { Supported or } \\
\text { not }\end{array}$ \\
\hline OPD $\rightarrow$ OC & $H_{1}$ & 0.64 & $5.85^{*}$ & Yes \\
\hline \multicolumn{4}{|c|}{ OPD: Organizational power distance, OC: Organizational commitment } \\
\hline
\end{tabular}

\subsection{The Structural Model}

After the scales were validated with measurement models using CFA, in this section, 1 main and 12 sub-hypothesis proposed within the scope of the study were tested using two different latent structure models. The Lisrel 8.7 program was used in structural equation modeling and validity and reliability analysis. The first hypothesis was tested in the model involving OPD and OC latent variables, while 12 sub-hypotheses were tested using latent variables representing sub-dimensions. Table 3 and 4 present the path coefficients and variance values of the latent variables in the models.

Figure 2 depicts the first path diagram for the main hypothesis whereas the chi-squared value $\left(\chi^{2}=32.88\right)$ and standard deviation $(\mathrm{SD}=14)$ are shown in Table 3. The ratio of the chi-squared value to the degrees of freedom $\left(\chi^{2} / S D=2.348\right)$ is less than 3 , indicating a perfect fit. Other goodness of fit indices for the structural model indicates that the established model gives a perfect fit. Figure 3

Table 4. Sub-hypotheses results

\begin{tabular}{|c|c|c|c|c|c|c|}
\hline \multicolumn{3}{|c|}{ Structural path } & \multirow{2}{*}{$\begin{array}{c}\text { Hypothesis } \\
H_{1.1 .} \\
\end{array}$} & \multirow{2}{*}{$\begin{array}{c}\text { Standard value } \\
0.17 \\
\end{array}$} & \multirow{2}{*}{$\begin{array}{c}\text { T-value } \\
2.98^{*} \\
\end{array}$} & \multirow{2}{*}{$\begin{array}{c}\text { Supported or not } \\
\text { Yes } \\
\end{array}$} \\
\hline $\mathrm{AOP}$ & $\rightarrow$ & $\mathrm{CC}$ & & & & \\
\hline $\mathrm{AOP}$ & $\rightarrow$ & $\mathrm{AC}$ & $H_{1.2 .}$ & 0.04 & 0.80 & No \\
\hline AOP & $\rightarrow$ & MC & $H_{1.3 .}$ & 0.24 & $4.29 *$ & Yes \\
\hline IUOP & $\rightarrow$ & $\mathrm{CC}$ & $H_{1.4}$ & 0.05 & 0.83 & No \\
\hline IUOP & $\rightarrow$ & $\mathrm{AC}$ & $H_{1.5 .}$ & -0.08 & -1.35 & No \\
\hline IUOP & $\rightarrow$ & $\mathrm{MC}$ & $H_{1.6 .}$ & 0.02 & 0.36 & No \\
\hline JOP & $\rightarrow$ & $\mathrm{CC}$ & $H_{1.7 .}$ & 0.01 & 0.17 & No \\
\hline JOP & $\rightarrow$ & $\mathrm{AC}$ & $H_{1.8 .}$ & 0.06 & 1.18 & No \\
\hline JOP & $\rightarrow$ & $\mathrm{MC}$ & $H_{1.9}$ & 0.12 & $2.31^{*}$ & Yes \\
\hline $\mathrm{AP}$ & $\rightarrow$ & $\mathrm{CC}$ & $H_{1.10 .}$ & 0.17 & $2.82 *$ & Yes \\
\hline $\mathrm{AP}$ & $\rightarrow$ & $\mathrm{AC}$ & $H_{1.11 .}$ & 0.18 & $3.04 *$ & Yes \\
\hline $\mathrm{AP}$ & $\rightarrow$ & $\mathrm{MC}$ & $H_{1.12 .}$ & 0.16 & $2.68^{*}$ & Yes \\
\hline
\end{tabular}

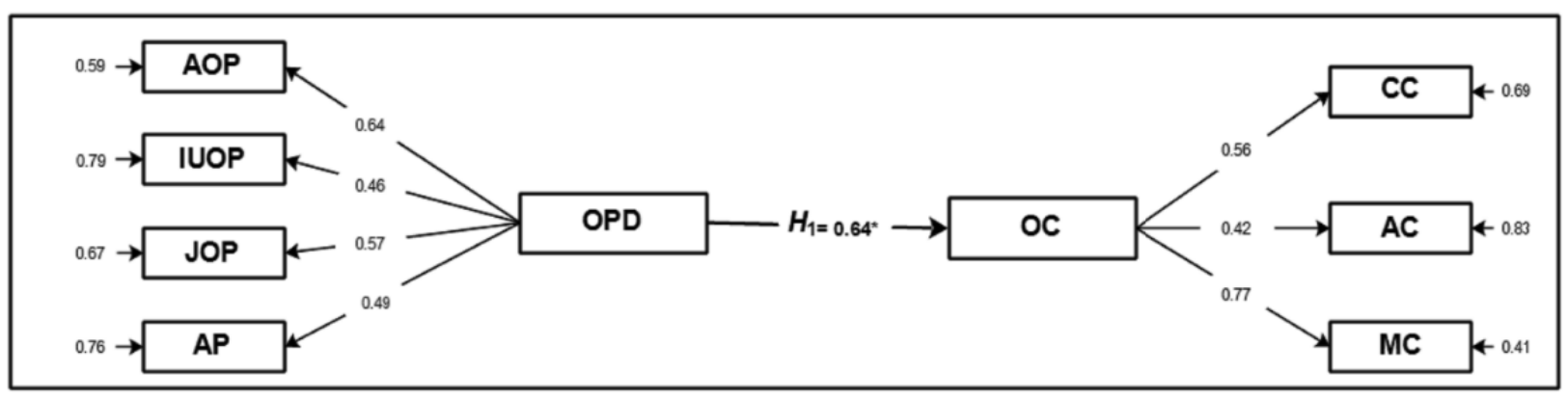

Figure 2. Path diagram for the main hypothesis

Chi-square $=32.88, d f=14, p$-value $=0.00101$, RMSEA $=0.066$

IUOP: Instrumental use of power, AOP: Acceptance of power, JOP: Justification of power, AP: Acquiescence of power, CC: Calculative commitment, AC: Alienative commitment, MC: Moral commitment, OPD: Organizational power distance, OC: Organizational commitment 


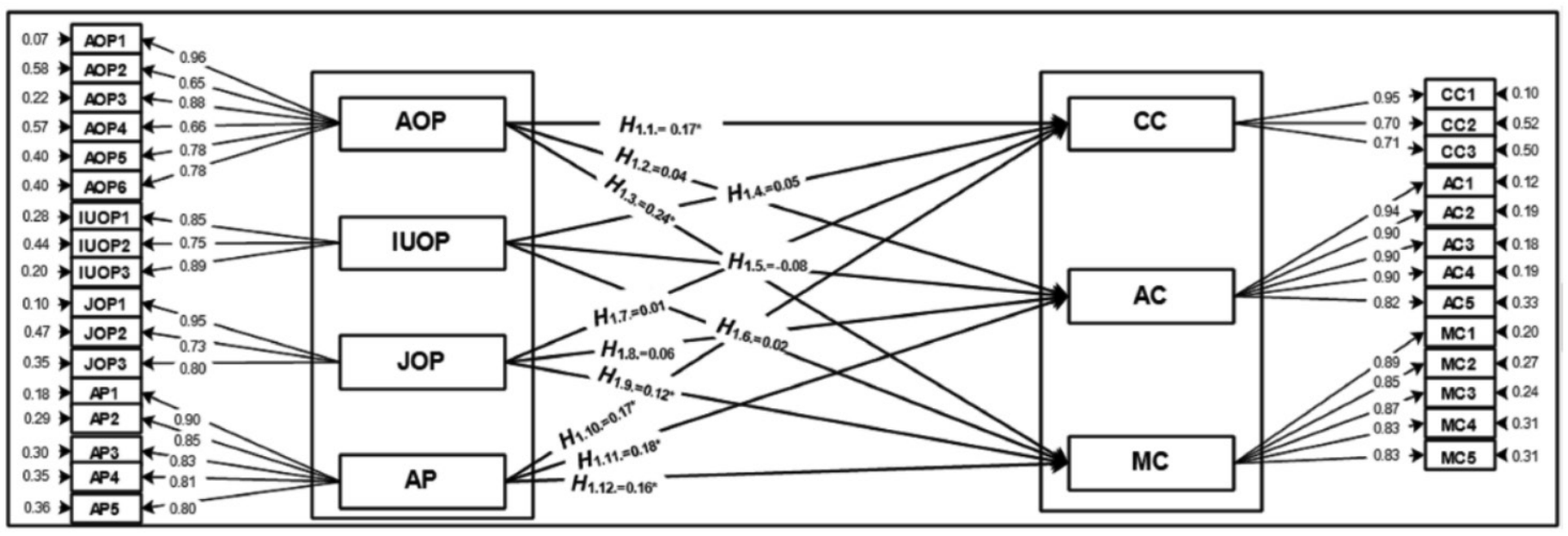

Figure 3. Path diagram for the sub-hypotheses

Chi-square $=769.73, d f=386, p$-value $=0.00000, R M S E A=0.050$

IUOP: Instrumental use of power, AOP: Acceptance of power, JOP: Justification of power, AP: Acquiescence of power, CC: Calculative commitment, AC: Alienative commitment, MC: Moral commitment

presents the second path diagram for the sub-hypotheses whereas the chi-squared value $\left(\chi^{2}=769.73\right)$ and standard deviation $(S D=386)$ are presented in Table 4 . The ratio of the chi-squared value to the degrees of freedom $\left(\chi^{2}\right)$ $\mathrm{SD}=1.994)$ is less than 3 , indicating a perfect fit. The other goodness of fit indices for the structural model indicates that the established model gives a perfect fit, as in the first model. The path coefficients of the OPD variable on the OC variable were significant $(0.64 ; \mathrm{p}<0.05)$ based on the path analysis results shown in Figure 2. The path analysis results in Figure 3 indicate that the path coefficients of AOP on CC $(0.17 ; \mathrm{p}<0.05)$, AOP on MC $(0.24 ; \mathrm{p}<0.05)$, JOP on MC (0.12; $\mathrm{p}<0.05)$, including AP on CC $(0.17 ; \mathrm{p}<0.05), \mathrm{AC}(0.18$; $\mathrm{p}<0.05)$ and $\mathrm{MC}(0.16 ; \mathrm{p}<0.05)$ were all significant.

Table 3 presents the main hypothesis results for this study, and power distance has a positive effect on the organizational commitment of students. This result indicates that the primary hypothesis $H_{1}$ is supported. Table 4 presents subhypotheses results. Our findings show that acceptance of power positively affects calculative and moral commitment, supporting sub-hypotheses $H_{1.1}$ and $H_{1.3 .}$ However, $H_{1.2 .}$ is not supported because acceptance of power does not affect alienative commitment. The results of the analysis show that instrumental use of power does not affect calculative commitment $\left(H_{1.4}\right)$, alienative commitment $\left(H_{1.5}\right)$, and moral commitment $\left(H_{1.6}\right)$. Although justification of power has a positive effect on moral commitment, it does not have a significant impact on calculative and alienative commitment. Therefore, sub-hypothesis $H_{1.9}$ is supported, while $H_{1.7 .}$ and $H_{1.8}$ are not. Finally, Table 4 shows that acquiescence of power positively affects calculative, alienative, and moral commitment. For this reason, sub-hypotheses $H_{1.10}, H_{1.11}$, and $H_{1.12 .}$ are supported.

\section{Discussion}

In this study, the effects of organizational power distance on organizational commitment were examined by considering the sub-dimensions of both concepts. The results of the present study demonstrated that the organizational power distance level of maritime faculty students had a significant and positive effect on their organizational commitment. These results are similar to those for some studies reported in the literature $[44,45]$ and showed that students take the social class they belong to as a criterion while exhibiting their behaviors based on class norms in their institutions. Moreover, the subordinate-superior relationship, one of the important building blocks of maritime customs, has a critical directive effect on their behavior rather than the necessity of legal rules or an egalitarian understanding.

When the sub-hypotheses were evaluated, maritime faculty students' acceptance of power tendency had a positive impact on their calculative and moral commitment. Conversely, no positive effect on their alienative commitment could be identified. These results are in agreement with some literature studies $[8,46]$.

Our data revealed that the instrumental use of power tendency of students did not affect their calculative, alienative, or moral commitment. This result is based on a study showing that a high level of organizational commitment can negatively affect both individuals and organizations [34]. In contrast, a study reports that employees with a high level of emotional organizational 
commitment adopt behaviors that benefit the organization by combining the organization's goals with their own goals [47].

The present study determined that although the students' tendency toward justification of power had a positive impact on their moral commitment, it did not affect their calculative and alienative commitment. Also, the present study supports the results of a study arguing that a high level of moral commitment in the individual corresponds to a strong bond and sense of duty toward the organization [9]. In this regard, this study could be the first to show that justification of power can have a positive impact on moral commitment.

The present results showed that maritime students' tendency to acquiescence of power positively affected their calculative, alienative, and moral commitments. Further, this result supports those of the study conducted by Bedürk and Ertürk [31]. The discipline, customs, and rules governing the hierarchical structure of an organization can be attributed to the positive effect that students' tendency to acquiescence of power had on their organizational commitment levels. It is possible to obtain such a result from the study because this understanding has long been accepted. Students accept this understanding from the beginning and participate in the organization on their own.

\section{Conclusion}

In the present research, a multidimensional examination of the effects of power distances, as perceived by maritime faculty students, on their organizational commitment was performed. The main conclusions of the study are as follows:

1. The present results support the previous studies arguing that power distance and organizational commitment do not completely represent the attitudes of participants in onedimensional models.

2. The results show that although power distance has positive effects on the organizational commitment levels of maritime students, it can have adverse effects in multidimensional evaluations.

3. The results support previous studies that found organizations with high power distance levels to have positive effects on individuals.

4. The organizational power distance perceived by students has a high level of influence on their organizational commitment because students studying in a hierarchical structure establish a strong bond with their institution. Besides, the normative education approach is dominant in the educational institution due to the nature of maritime shows that it has a significant impact on the behavior of students.
5. The results shall contribute valuable information to the literature by identifying the commitment level that students studying in a hierarchical structure have toward their institution and explaining the underlying reasons.

The maritime faculty students are prepared for international working areas. They have their own discipline, customs, and rules and are trained for the difficulties encountered in their working conditions, which differentiate them from those studying other disciplines. To put it more clearly, the organizational commitment levels of students educated in a hierarchical structure may differ from those studying other programs. Therefore, it is necessary to exercise caution when generalizing the results of this study for students in other departments. Moreover, in this study, the factors affecting the organizational commitment levels of maritime faculty students were evaluated only by considering the concept of power distance and its sub-dimensions. The concept of organizational power distance was associated with four sub-dimensions and the concept of organizational commitment with three sub-dimensions. However, other studies in the literature have linked these concepts to different dimensions. Therefore, using different sample groups and dimensions and an extensive examination of the topic would contribute to the literature in future studies.

\section{Authorship Contributions}

Concept design: U. Ylldırım, A.L. Tunçel, Data Collection or Processing: U. Yıldırım, A. Toygar, A.L. Tunçel, Analysis or Interpretation: U. Ylldırım, A. Toygar, Literature Review: U. Yıldırım, A. Toygar, A.L. Tunçel, Writing, Reviewing and Editing: U. Ylldırım, A. Toygar, A.L. Tunçel.

Funding: The author(s) received no financial support for the research, authorship, and/or publication of this article.

\section{References}

[1] J. A. Ross, and P. Gray, "Transformational leadership and teacher commitment to organizational values: The mediating effects of collective teacher efficacy." School Effectiveness and School Improvement, vol. 17, pp. 179-199, May 2006.

[2] S. Wilkins, M. M. Butt, D. Kratochvil, and M. S. Balakrishnan, "The effects of social identification and organizational identification on student commitment, achievement and satisfaction in higher education." Studies in Higher Education, vol. 41, pp. 2232-2252, Dec 2016.

[3] A. A. Khan, S. B. Asimiran, S. A. Kadir, S. N. Alias, B. Atta, B. A. Bularafa, and M. U. Rehman, "Instructional leadership and students academic performance: Mediating effects of teacher's organizational commitment," International Journal of Learning, Teaching and Educational Research, vol. 19, pp. 233-247, May 2020.

[4] L. Rhoades, and R. Eisenberger, "Perceived organizational support: A review of the literature." Journal of Applied Psychology, vol. 87, pp. 698-714, Feb 2002. 
[5] L. Tanggaard, "Collaborative teaching and learning in the workplace." Journal of Vocational Education and Training, vol. 57, pp. 109-122, Mar 2005.

[6] S. Nas, and B. Celik, "The academician profiles of maritime higher education institutions in Turkey." Journal of ETA Maritime Science, vol. 1, pp. 7-14, Mar 2013.

[7] B. L. Kirkman, G. Chen, J. L. Farh, Z. X. Chen, and K. B. Lowe, "Individual power distance orientation and follower reactions to transformational leaders: A crosslevel, cross-cultural examination." Academy of Management Journal, vol. 52, pp. 744764, Aug 2009.

[8] H. Wang, X. Han, and J. Li. "Supervisor narcissism and employee performance: A moderated mediation model of affective organizational commitment and power distance orientation." Basic and Applied Social Psychology, vol. 43, pp. 14-29, 2021.

[9] S. J. Jaros, J. M. Jermier, J. W. Koehler, and T. Sincich, "Effects of continuance, affective, and moral commitment on the withdrawal process: An evaluation of eight structural equation models." Academy of Management Journal, vol. 36, pp. 951-995, 1993.

[10] M. Mulder, The daily power game. Leiden, Netherlands: Martinus Nijhoff, Social Science Division, 1977.

[11] G. Hofstede, "The cultural relativity of organizational practices and theories." Journal of International Business Studies, vol. 14, pp. 75-89, 1983.

[12] Y. İ. Yorulmaz, İ. Çolak, Y. Altınkurt, and K. Yılmaz, "The validity and reliability study of organizational power distance scale." Trakya Journal of Education, vol. 8, pp. 671-686, Sep 2018.

[13] G. Hofstede, "Cultures and organizations: Software of the mind." New York, NY: McGraw-Hill, 1997.

[14] H. T. T. Duong, and D. T. T. Thuy, "Factors affecting organizational commitment of students in foreign trade university's clubs." Journal International Economics and Management, vol. 124, pp. 65-87, 2019.

[15] J. P. Meyer, and N. J. Allen, "A three-component conceptualization of organizational commitment." Human Resource Management Review, vol. 1, pp. 61-89, 1991.

[16] M. E. Sheldon, "Investments and involvements as mechanisms producing commitment to the organization." Administrative Science Quarterly, vol. 16, pp. 143-150, Apr 1971.

[17] B. Buchanan, "Building organizational commitment: The socialization of managers in work organizations." Administrative Science Quarterly, vol. 19, pp. 533-546, Oct 1974. https://doi. org/10.2307/2391809.

[18] G. Çöl, and H. Gül, "Kişisel özelliklerin örgütsel bağlılık üzerine etkileri ve kamu üniversitelerinde bir uygulama." Atatürk Üniversitesi Íktisadi ve İdari Bilimler Dergisi, vol. 19, pp. 291-306, Oct 2005.

[19] A. Etzioni, A comparative analysis of complex organizations. Revised and enlarged edition. New York, NY: The Free Press, 1975.

[20] L. E. Penley, and S. Gould, "Etzioni's model of organizational involvement: A perspective for understanding commitment to organizations." Journal of Organizational Behavior, vol. 9, pp. 4359, Mar 1988.

[21] J. L. Farh, R. D. Hackett, and J. Liang, "Individual-level cultural values as moderators of perceived organizational support- employee outcome relationships in China: Comparing the effects of power distance and traditionality." Academy of Management Journal, vol. 50, pp. 715-729, Jun 2007.

[22] B. Ylldırım, and A. Deniz "The relationship between power distance and organizational commitment in primary schools." Educational Research and Reviews, vol. 9, pp. 750-760, Oct 2014.

[23] S. Rafiei, and A. Pourreza, "The moderating role of power distance on the relationship between employee participation and outcome variables." International Journal of Health Policy and Management, vol. 1, pp. 79-83, Jun 2013.

[24] M. S. Din, M. Bashir, K. U. R. Cheema, and S. S. Zafar, "The role of power distance in the relationship between employee motivation and organizational commitment: A study on education sector of Pakistan." IOSR Journal of Business and Management, vol. 16, pp. 9-18, Jan 2014.

[25] S. Hornung, "Alienation matters: Validity and utility of etzioni's theory of commitment in explaining prosocial organizational behavior." Social Behavior and Personality, vol. 38, pp. 10811096, Sep 2010.

[26] S. A. Duska, "Harmony ideology and dispute resolution: A legal ethnography of the tibetan diaspora in India." PhD thesis. The University of British Columbia, Vancouver, 2008.

[27] H. Ergün, and K. Çelik, "Adaptation of organizational commitment scale into Turkish language." Pamukkale University Journal of Social Science Institute, vol. 34, pp. 113-121, Jan 2019.

[28] [28] E. E. Tsahuridu, "Knowledge is power/power corrupts: Should we empower people at work?" in World Ethics Forum (WEF) Conference Proceedings, C. Sampford and C. Connors, Eds. Oxford, United Kingdom: The Institute for Ethics, Governance and Law. 2007, pp. 379-385.

[29] M. Z. A. Rashid, M. Sambasivan, and J. Johari, "The influence of corporate culture and organisational commitment on performance." Journal of Management Development, vol. 22, pp. 708-728, Oct 2003.

[30] J. Berger, C. L. Ridgeway, M. H. Fisek, and R. Z. Norman, "The legitimation and delegitimation of power and prestige orders." American Sociological Review, vol. 63, pp. 379-405, Jun 1998

[31] A. Bedürk, and E. Ertürk, "The impact of power distance and organizational justice perceptions on the organizational citizenship behaviour in the context of social exchange theory." The Journal of Business Science, vol. 3, pp. 1-19, 2015.

[32] V. O. Pomyalova, N. V. Volkova and O. V. Kalinina, "Effect of the university organizational culture perception on students' commitment: The role of organizational identification." IOP Conf. Series: Materials Science and Engineering, 940, 012099, Oct 2020.

[33] D. Javeline, "Response effects in polite cultures: A test of acquiescence in Kazakhstan." Public Opinion Quarterly, vol. 63, pp. 1-28, 1999.

[34] D. M. Randall, "Commitment and the organization: The organization man revisited." Academy of Management Review, vol. 12, pp. 460-471, Jul 1987.

[35] U. Sekaran, and R. Bougie "Research methods for business: A skill-building approach. $7^{\text {th }}$ Ed. UK: John Wiley \& Sons, 2016.

[36] J. Cohen, "Statistical power analysis for the behavioral sciences." $2^{\text {nd }}$ Ed. Hillsdale, NJ: Lawrence Erlbaum, 1998. 
[37] T. A. Brown, "Confirmatory factor analysis for applied research." $2^{\text {nd }}$ Ed. New York, NY: The Guilford Press, 2015.

[38] J. F. Hair, R. E. Anderson, R. L. Tatham, and W. C. Black, "Analisis Multivariante." Madrid: Prentice Hall, 1999.

[39] R. P. Bagozzi, and Y. Yi, "On the evaluation of structural equation models." Journal of the Academy of Marketing Science, vol. 16, pp. 74-94, 1988.

[40] C. Fornell, and D. F. Larcker, "Evaluating structural equation models with unobservable variables and measurement error." Journal of Marketing Research, vol. 18, pp. 39-50, 1981.

[41] J.C. Nunally, "Psychometric Theory," New York, NY: McGraw-Hill, 1967.

[42] K. Schermelleh-Engel, H. Moosbrugger and H. Müller "Evaluating the fit of structural equation models: Tests of significance and descriptive goodness-of-fit measures." Methods of Psychological Research Online, vol. 8, pp. 23-74, 2003.

[43] P. M. Bentler, and D. G. Bonett, "Significance tests and goodness of fit in the analysis of covariance structures." Psychological Bulletin, vol. 88, pp. 588-606, 1980.
[44] H. Gul, M. Usman, Y. Liu, Z. Rehman, and K. Jebran, "Does the effect of power distance moderate the relation between person environment fit and job satisfaction leading to job performance? Evidence from Afghanistan and Pakistan." Future Business Journal, vol. 4, pp. 68-83, Jun 2018.

[45] T. Uzun, "Relationships between power distance, organizational commitment, and trust in schools." Educational Policy Analysis and Strategic Research, vol. 15, pp. 359-371, 2020.

[46] A. P. Athanasios, and K. Y. Ng. Adolf, "Pursuing maritime education: an empirical study of students' profiles, motivations and expectations." Maritime Policy \& Management, vol. 38, pp. 369-393, Feb 2011.

[47] C. A. O'Reilly, and J. Chatman, "Organizational commitment and psychological attachment: The effects of compliance, identification, and internalization on prosocial behavior." Journal of Applied Psychology, vol. 71, pp. 492-499, 1986. 